\title{
Article
}

\section{Fabrication of Ce-doped MnO2 decorated graphene sheets for fire safety applications of epoxy composites: flame retardancy, smoke suppression and mechanism}

Jiang, Shu-Dong, Bai, Zhi-Man, Tang, Gang, Song, Lei, Stec, Anna A, Hull, T Richard, Zhan, Jing and Hu, Yuan

Available at http://clok.uclan.ac.uk/11652/

Jiang, Shu-Dong, Bai, Zhi-Man, Tang, Gang, Song, Lei, Stec, Anna A ORCID: 0000-0002-6861-0468, Hull, T Richard ORCID: 0000-0002-7970-4208, Zhan, Jing and Hu, Yuan (2014) Fabrication of Ce-doped MnO2 decorated graphene sheets for fire safety applications of epoxy composites: flame retardancy, smoke suppression and mechanism. Journal of Materials Chemistry, 2 (41). pp. 17341-17351. ISSN 0959-9428

It is advisable to refer to the publisher's version if you intend to cite from the work. http://dx.doi.org/10.1039/c4ta02882a

For more information about UCLan's research in this area go to http://www.uclan.ac.uk/researchgroups/ and search for <name of research Group>.

For information about Research generally at UCLan please go to http://www.uclan.ac.uk/research/

All outputs in CLoK are protected by Intellectual Property Rights law, including Copyright law. Copyright, IPR and Moral Rights for the works on this site are retained by the individual authors and/or other copyright owners. Terms and conditions for use of this material are defined in the policies page. 


\title{
Fabrication of Ce-doped $\mathrm{MnO}_{2}$ decorated graphene sheets for fire safety applications of epoxy composites: flame retardancy, smoke suppression and mechanism
}

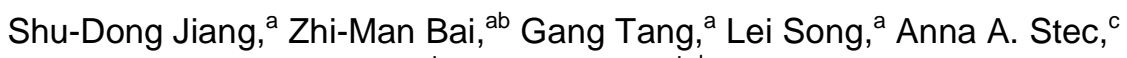 \\ T. Richard Hull, ${ }^{c}$ Jing Zhan ${ }^{\star a}$ and Yuan Hu${ }^{\star a b}$
}

Ce-doped $\mathrm{MnO}_{2}$-graphene hybrid sheets were fabricated by utilizing an electrostatic interaction between Ce-doped $\mathrm{MnO}_{2}$ and graphene sheets. The hybrid material was analyzed by a series of characterization methods. Subsequently, the Ce-doped $\mathrm{MnO}_{2}-\mathrm{graphene}$ hybrid sheet was introduced into an epoxy resin, and the fire hazard behaviors of the epoxy nanocomposite were investigated. The results from thermogravimetric analysis exhibited that the incorporation of $2.0 \mathrm{wt} \%$ of Ce-doped $\mathrm{MnO}_{2}$-graphene sheets clearly improved the thermal stability and char residue of the epoxy matrix. In addition, the addition of $\mathrm{Ce}-\mathrm{MnO}_{2}-$ graphene hybrid sheets imparted excellent flame retardant properties to an epoxy matrix, as shown by the dramatically reduced peak heat release rate and total heat release value obtained from a cone calorimeter. The results of thermogravimetric analysis/infrared spectrometry, cone calorimetry and steady state tube furnace tests showed that the amount of organic volatiles and toxic CO from epoxy decomposition were significantly suppressed after incorporating $\mathrm{Ce}-\mathrm{MnO}_{2}$-graphene sheets, implying that this hybrid material has reduced fire hazards. A plausible flame-retardant mechanism was hypothesized on the basis of the characterization of char residues and direct pyrolysis- mass spectrometry analysis: during the combustion, $\mathrm{Ce}-\mathrm{MnO}_{2}$, as a solid acid, results in the formation of pyrolysis products with lower carbon numbers. Graphene sheets play the role of a physical barrier that can absorb the degraded products, thereby extend their contact time with the metal oxides catalyst, and then promote their propagate on the graphene sheets; meanwhile pyrolysis fragments with lower carbon numbers can be easily catalyzed in the presence of $\mathrm{Ce}-\mathrm{MnO}_{2}$. The notable reduction in the fire hazards was mainly attributed to the synergistic action between the physical barrier effect of graphene and the catalytic effect of Ce- $\mathrm{MnO}_{2}$.

\section{Introduction}

Epoxy resin (EP) is one of the most widely exploited reactive polymeric resins in the laminating, adhesive, coating and casting fields due to its high tensile strength and modulus, low shrinkage when cured, high adhesion property, excellent dimensional stability and chemical and corrosion resistance. ${ }^{1,2}$ However, the high flammability and large yield of smoke and toxic gases during combustion significantly restricts their application in some areas. Recently, nanocomposite technology

${ }^{a}$ State Key Laboratory of Fire Science, University of Science and Technology of China, Anhui 230026, P. R. China. E-mail: yuanhu@ustc.edu.cn; Fax: +86 551 63601664; Tel: +8655163601664

${ }^{b}$ Suzhou Key Laboratory of Urban Public Safety, Suzhou Institute for Advanced Study, University of Science and Technology of China, 166 Ren'ai Road, Suzhou, Jiangsu 215123, P. R. China

${ }^{c}$ Centre for Fire and Hazards Science, University of Central Lancashire, Preston PR1 $2 H E, U K$ has brought a revolutionary advancement in the flame-retardant research community. For example, the incorporation of nano-fillers, such as layered silicates and layered double hydroxides (LDHs), can efficiently improve the fire resistance of polymer nanocomposites. ${ }^{1-3}$ However, a key problem that was realized in this system is that the large addition of fillers required $(>20 \mathrm{wt} \%)$ resulted in the deterioration of other properties, which is undesirable for fabricating high performance materials.

Graphene, a two-dimensional (2D) form of carbon, has become a 'rising star' because of its large specific surface area, extraordinarily high electrical and superior mechanical strength. ${ }^{4-6}$ Very recently, similar to some other members of the family of carbon-based materials, such as expanded graphite, graphite oxide and carbon nanotubes, graphene has attracted interests in scientific field as a flame retardant additive. ${ }^{7,8} \mathrm{Kim}$ et $a .^{9}{ }^{9}$ demonstrated that graphene is actually thermally stable even after exposing it to a flame, clearly 
indicating the high intrinsic flame resistance of graphene. In addition, there are some other reports regarding the application of graphene as a flame retardant additive in polymer composites. ${ }^{10-13}$ However, bare graphene was used as a flame retardant in previous reports, such that a high loading is required to achieve a good flame retardant effect. Therefore, the use of graphene alone as the flame retardant still remains a challenge.

As an important functional metal oxide, manganese oxide has received considerable interest due to its distinctive physical and chemical properties, which lead to its application in catalysis, ${ }^{14}$ adsorption, ${ }^{15}$ and flame retardation. ${ }^{16}$ It has also been found that compounds containing cerium also have an unusually wonderful effect of flame-reduction in polymers. ${ }^{17}$ Recently, intensive studies have focused on combining two or more components, which can present a synergistic effect and may offer an unexpected flame resistance to polymers. Tang et al. demonstrated a novel catalytic method to endow polypropylene with obviously enhanced fire resistance in the presence of clay and a supported nickel catalyst. ${ }^{18} \mathrm{Yu}$ et el. showed a synergism between multiwalled carbon nanotubes and $\mathrm{Ni}_{2} \mathrm{O}_{3}$ on the flame retardancy of polyethylene. ${ }^{19}$ Levchik et al. observed that the integration of $\mathrm{Sb}_{2} \mathrm{O}_{3}$ and $\mathrm{ZnS}$ generated a synergistic effect for the flame retardance and smoke suppression of poly(vinyl chloride). ${ }^{20}$ Inspired by these, this study aims to improve the fire hazards of EP by combining graphene sheets and $\mathrm{Ce}-\mathrm{MnO}_{2}$.

In this work, a hybrid of $\mathrm{Ce}-\mathrm{MnO}_{2}$ decorated graphene sheets $\left(\mathrm{Ce}-\mathrm{MnO}_{2}-\mathrm{GNS}\right)$ were synthesized by co-assembly between positively charged $\mathrm{Ce}-\mathrm{MnO}_{2}$ nanoparticles and negatively charged graphene sheets (GNS). GNS have a negative charge nature due to the presence of a small amount of carboxyl, epoxy and hydroxyl groups. ${ }^{21}$ In addition, modified $\mathrm{Ce}-\mathrm{MnO}_{2}$ with $\mathrm{NH}_{2}$ groups exhibited the positive charge nature. The self-assembly of charged nanomaterials via electrostatic interactions is a controllable route for gener-

ating hybrid materials in an aqueous environment. ${ }^{22-24}$ Thus,

the self-assembly of GNS and $\mathrm{Ce}-\mathrm{MnO}_{2}$ could simply be carried out by utilizing the electrostatic interactions between

the negative charge of GNS and the positive charge of modified $\mathrm{Ce}-\mathrm{MnO}_{2}$. Subsequently, a $\mathrm{Ce}-\mathrm{MnO}_{2}-\mathrm{GNS}$ hybrid was added into EP for the investigation of reduced fire hazards behavior. The synergistic effects between $\mathrm{Ce}-\mathrm{MnO}_{2}$ and GNS for thermal stability, fire resistance and smoke suppression properties of the as-prepared nanocomposite were systematically investigated by thermogravimetric analysis (TGA), cone calorimetry, steady state tube furnace (SSTF) and thermogravimetric analysis/infrared spectrometry (TGIR). Interestingly, it was found that a number of properties of the resultant nanocomposite could be remarkably enhanced. Meanwhile, the flame-retardant mechanism was studied by the analysis of the char residue and pyrolysis fragments. Such an aqueous synthetic strategy may be potentially applicable to the fabrication of other inorganic materialsGNS hybrids, which have potential applications in flame retardant field.

\section{Experimental section}

\subsection{Materials}

Graphite powder, concentrated sulfuric acid (98\%), sodium nitrate, $\mathrm{KMnO}_{4}, 30 \% \mathrm{H}_{2} \mathrm{O}_{2}$ solution, hydrochloric acid, hydrazine hydrate $(80 \%)$ and $\mathrm{Ce}\left(\mathrm{NO}_{3}\right)_{3} \cdot 6 \mathrm{H}_{2} \mathrm{O}, \mathrm{HNO}_{3}$ were purchased from Sinopharm Chemical Reagent Co. Ltd. (Shanghai, China). Aminopropyltriethoxysilane (APTES, 99\%) was obtained from Aldrich (America). All the starting chemicals were of analytical grade and were used without further purification. Deionized water was used as the solvent.

\subsection{Synthesis of GNS}

Graphite oxide (GO) was first synthesized from graphite powder by the Hummers method, and then the aqueous GO disper sion was chemically reduced by hydrazine to generate a GNS, as described elsewhere. The obtained GNS was centrifuged, washed with absolute ethanol and then dried under vacuum. The yield of the final GNS was about $70 \%$.

\subsection{Synthesis of $\mathrm{Ce}-\mathrm{MnO}_{2}$}

Typically, $0.003 \mathrm{~mol}$ of $\mathrm{KMnO}_{4}$ and $0.00085 \mathrm{~mol}$ of $\mathrm{Ce}\left(\mathrm{NO}_{3}\right)_{3} \cdot 6 \mathrm{H}_{2} \mathrm{O}$ were dissolved in $35 \mathrm{~mL}$ of deionized water, followed by the addition of $2 \mathrm{~mL}$ concentrated $\mathrm{HNO}_{3}$ (16 mol L ${ }^{-1}$ ) under magnetic stirring. The solution was transferred to a Teflon-lined autoclave $(50 \mathrm{~mL})$, maintained at $140{ }^{\circ} \mathrm{C}$ for $3 \mathrm{~h}$, and then finally cooled to room temperature. After washing with $30 \mathrm{~mL}$ of distilled water and $30 \mathrm{~mL}$ of ethanol three times, brown black precipitates were obtained, which were then dried at $60{ }^{\circ} \mathrm{C}$ overnight. The yield of the final Ce$\mathrm{MnO}_{2}$ was $85 \%$.

\subsection{Electrostatic assembly of $\mathrm{Ce}-\mathrm{MnO}_{2}-\mathrm{GNS}$ hybrid}

The $\mathrm{Ce}-\mathrm{MnO}_{2}$ nanoparticles were first reacted with APTES to modify their surface with $\mathrm{NH}_{2}$ groups. ${ }^{27}$ The self-assembly of GNS and $\mathrm{Ce}-\mathrm{MnO}_{2}$ was carried out by electrostatic interactions. Briefly, $0.09 \mathrm{~g}$ of modified $\mathrm{Ce}-\mathrm{MnO}_{2}$ and $0.009 \mathrm{~g}$ GNS were added to $60 \mathrm{~mL}$ of $\mathrm{H}_{2} \mathrm{O}$ under ultrasonic agitation for $5 \mathrm{~h}$. The $\mathrm{Ce}-\mathrm{MnO}_{2}-\mathrm{GNS}$ hybrid was obtained after centrifugation and washing with $50 \mathrm{~mL}$ of water, and then dried in air at $60{ }^{\circ} \mathrm{C}$. The yield of the final $\mathrm{Ce}-\mathrm{MnO}_{2}-\mathrm{GNS}$ hybrid was about $90 \%$.

\subsection{Preparation of Ce- $\mathrm{MnO}_{2}-\mathrm{GNS}-\mathrm{EP}$ composite}

Typically, the preparation of epoxy composite with $2 \mathrm{wt} \% \mathrm{Ce}-$ $\mathrm{MnO}_{2}-\mathrm{GNS}$ hybrid was as follows: $\mathrm{Ce}-\mathrm{MnO}_{2}-\mathrm{GNS}(0.2 \mathrm{~g})$ hybrid was dispersed into tetrahydrofuran and ultrasonically mixed until the $\mathrm{Ce}-\mathrm{MnO}_{2}-\mathrm{GNS}$ was completely dispersed to form a black suspension. Then, epoxy resin (8.2 g) and $4,4^{0}$ diaminodiphenyl-methane (DDM, $1.6 \mathrm{~g}$ ) were introduced into the abovementioned suspension and stirred until homogeneous mixtures were obtained. The mixtures were heated in a vacuum oven at about $60{ }^{\circ} \mathrm{C}$ to remove excess solvent. Subsequently, the samples were cured at $100^{\circ} \mathrm{C}$ for $2 \mathrm{~h}$ and post cured at $150^{\circ} \mathrm{C}$ for $2 \mathrm{~h}$. After curing, the samples were cooled to room 
temperature. For other samples containing neat EP, Ce$\mathrm{MnO}_{2}-\mathrm{EP}$ and GNS-EP, similar synthetic procedures were deployed except that the additives were varied.

\subsection{Characterization}

The powder X-ray diffraction (XRD) patterns of the assynthesized samples were recorded with a Japan MapAHF Xray diffractometer equipped with graphite-monochromatized $\mathrm{Cu} \mathrm{K} \alpha$ irradiation $(\lambda=0.154056 \mathrm{~nm})$, employing a scanning rate of $0.02^{\circ} \mathrm{s}^{-1}$ in the $2 \theta$ range of $10-60^{\circ}$. Fourier transform infrared (FTIR) spectrum analyses were operated on samples pelletized with $\mathrm{KBr}$ powders in the range of $4000-400 \mathrm{~cm}^{-1}$ using an IR Fourier transform spectrophotometer (Nicolet, ZOSX). Raman spectroscopy measurements were carried out at room temperature with a SPEX-1403 laser Raman spectrometer(SPEX Co, USA) with excitation provided in the backscattering geometry by a $514.5 \mathrm{~nm}$ argon laser line. The microstructures of $\mathrm{Ce}-\mathrm{MnO}_{2}-\mathrm{GNS}$ were observed by a JEOL JSM-2010 field-emission scanning electron microscope

(SEM). Transmission electron microscopy (TEM) images were obtained on a Hitachi model H-800 transmission electron microscope with an accelerating voltage of $200 \mathrm{kV}$. Prior to observation, $\mathrm{Ce}-\mathrm{MnO}_{2}-\mathrm{GNS}$ were dispersed in deionized water followed by ultrasonication for $30 \mathrm{~min}$. The homogeneous mixtures were dripped on carbon-coated copper grids. $\mathrm{Ce}-\mathrm{MnO}_{2}-\mathrm{GNS}-\mathrm{EP}$ nanocomposite was cut into ultrathin sections using a CM1900 microtome (Leica, Wetzlar, Germany). The ultrathin sections were transferred from liquid nitrogen to carbon-coated copper grids and then observed by TEM. Energy-dispersive X-ray spectroscopy (EDS) analysis was obtained with an EDAX detector installed on the same TEM, and a copper grid was used. TGA of samples were carried out with a Q5000 thermal analyzer (TA Co., USA) from $50{ }^{\circ} \mathrm{C}$ to $700{ }^{\circ} \mathrm{C}$ at a heating rate of $20{ }^{\circ} \mathrm{C} \mathrm{min}^{-1}$ in an air atmosphere. X-ray photoelectron spectroscopy (XPS) spectra were recorded on an ESCALAB 250 X-ray photoelectron spectrometer employing a monochromatic Al Ka X-ray

source. TG-IR was performed using the TGA Q5000 IR thermogravimetric analyzer which was coupled with the Nicolet

6700 FT-IR spectrophotometer via a stainless steel transfer pipe. Direct pyrolysis-mass spectrometry (DP-MS) analysis

was performed with a Micromass GCT-MS spectrometer using the standard direct insertion probe for solid polymer materials at a heating rate of $15{ }^{\circ} \mathrm{C} \mathrm{min}^{-1}$ in the range of 30$700{ }^{\circ} \mathrm{C}$. The cone calorimeter test was carried out following the procedures given in ISO5660. Square specimens $(100 \times$ $100 \times 3 \mathrm{~mm}^{3}$ ) were irradiated at a heat flux of $35 \mathrm{~kW} \mathrm{~m}^{-2}$, corresponding to a mild fire scenario. The fire toxicity was assessed using a SSTF (ISO TS 19700), as shown in Scheme 1. An amount of sample (about $20 \mathrm{~g}$ ) in the form of granules or pellets, which was spread evenly along the furnace boat was introduced into a tube furnace at a constant rate. A current of air was passed through the furnace over the specimen to support combustion. The effluent was expelled from the tube furnace into a mixing chamber, where

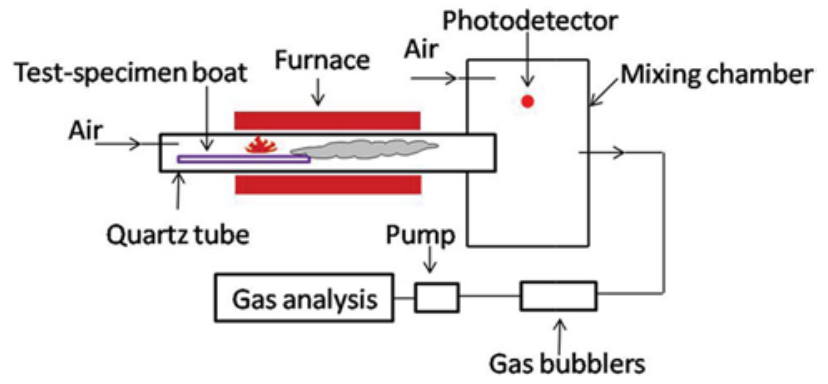

Scheme 1 Illustration of the steady state tube furnace.

carbon monoxide concentration and smoke density could be measured.

\section{Results and discussion}

\subsection{Characterization of $\mathrm{Ce}-\mathrm{MnO}_{2}-\mathrm{GNS}$ hybrid}

The composition and phase purity of GO, GNS, Ce- $\mathrm{MnO}_{2}$ and $\mathrm{Ce}-\mathrm{MnO}_{2}-\mathrm{GNS}$ were first examined by powder XRD, as depicted in Fig. 1A. For pure $\mathrm{Ce}-\mathrm{MnO}_{2}$, four relatively strong peaks appeared at $2 \theta$ of around $22.1,37.4,42.7$, and $56.7^{\circ}$, which are assigned to (120), (031), (300), and (160) reflections of the orthorhombic $\gamma-\mathrm{MnO}_{2}$, respectively, with lattice contents of $a=$ $6.3600 \AA \AA$ and $c=4.0900 \AA$ (JCPDS Card no. 14-0644). No signal for the phases of GNS (002) or GO (001) could be detected in the $\mathrm{Ce}-\mathrm{MnO}_{2}-\mathrm{GNS}$ hybrid. The relatively high content and good crystallinity of $\mathrm{Ce}-\mathrm{MnO}_{2}$ in the hybrid gave strong diffraction peaks, covering the diffraction of the GNS. ${ }^{28,29}$ Fig. $1 \mathrm{~B}$ shows the EDS spectrum of $\mathrm{Ce}-\mathrm{MnO}_{2}$, in which the signals for $\mathrm{Mn}$ and $\mathrm{O}$ with the atomic ratio of approximately $1: 2$ are clearly observed, indicating the chemical composition of $\mathrm{MnO}_{2} . \mathrm{Cu}$ and $\mathrm{C}$ elements come from the carbon-coated copper grid, which is used as the support for the characterization of the $\mathrm{Ce}-\mathrm{MnO}_{2}-\mathrm{GNS}$ hybrid. In addition, very small amounts of $\mathrm{Ce}$ are detected, indicating that $\mathrm{Ce}$ exists in the $\mathrm{MnO}_{2}$ structure.

The morphology and size of the $\mathrm{Ce}-\mathrm{MnO}_{2}-\mathrm{GNS}$ hybrid were characterized by TEM and SEM (Fig. 2). As can be observed from

Fig. 2A-D, Ce- $\mathrm{MnO}_{2}$ particles with different sizes were depos-

ited on the GNS, and the GNS showed a representative wrinkle and ripped shape. The TEM image of $\mathrm{Ce}-\mathrm{MnO}_{2}-\mathrm{GNS}-\mathrm{EP}$ composite is also provided (Fig. 2E), from which one can see the $\mathrm{Ce}-\mathrm{MnO}_{2}$ and GNS was still held together in the EP matrix.
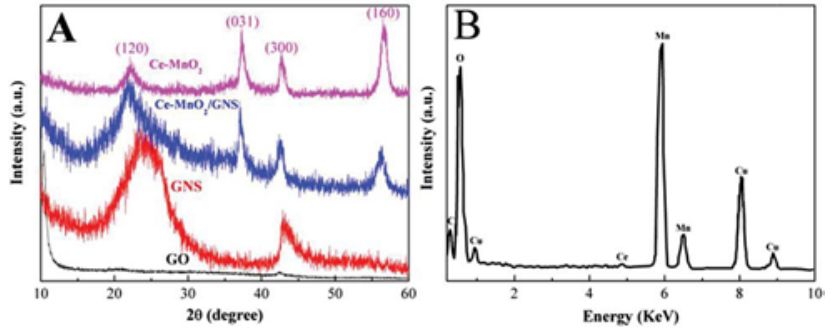

Fig. 1 Typical XRD patterns of $\mathrm{GO}, \mathrm{GNS}$ and $\mathrm{Ce}-\mathrm{MnO}_{2}-\mathrm{GNS}$ hybrids (A) and EDS spectrum (B) of the $\mathrm{Ce}-\mathrm{MnO}_{2}-\mathrm{GNS}$ hybrid. 


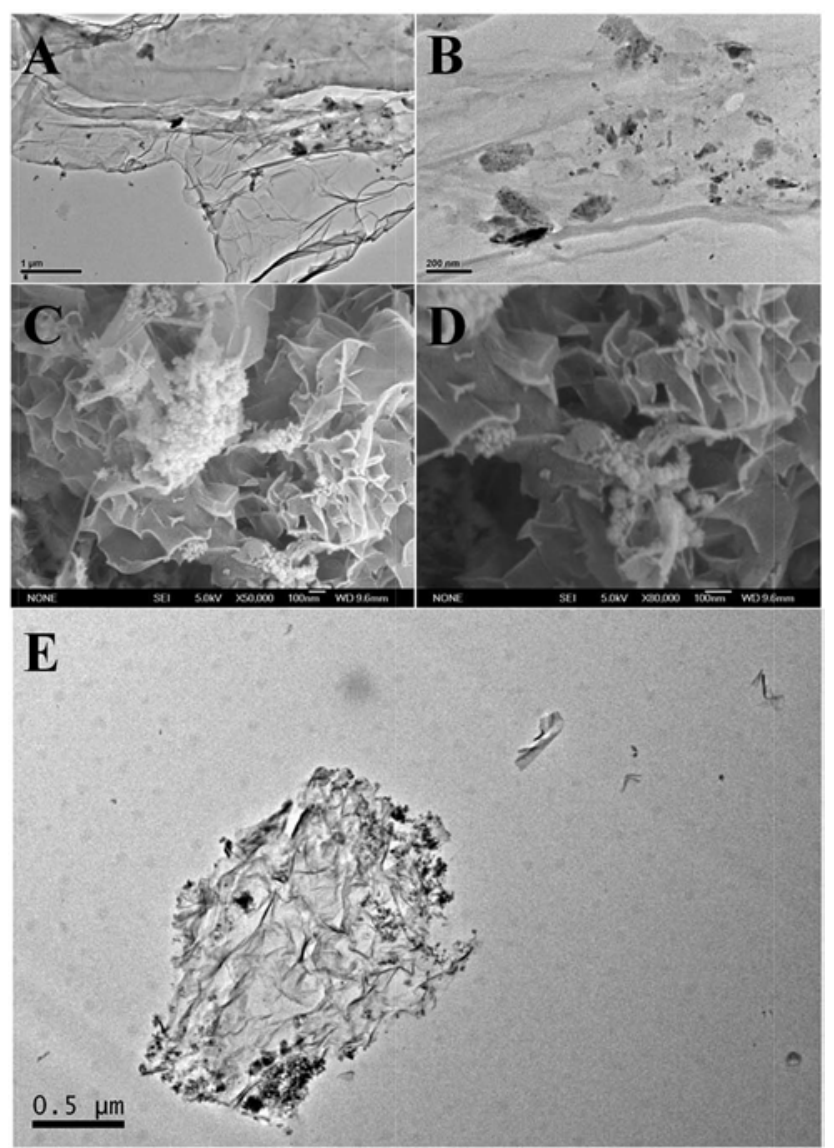

Fig. 2 TEM and SEM images of $\mathrm{Ce}-\mathrm{MnO}_{2}-\mathrm{GNS}$ hybrid (A-D), and TEM image of a Ce- $\mathrm{MnO}_{2}-\mathrm{GNS}-\mathrm{EP}$ ultrathin section (E).

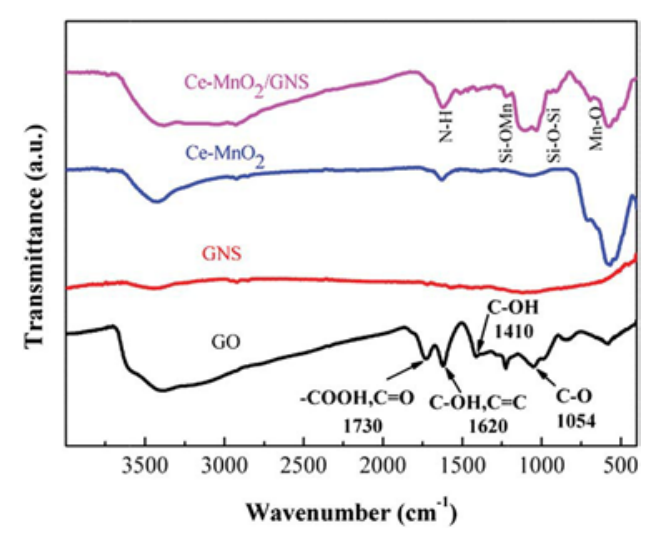

Fig. 3 FTIR spectra of GO, GNS, Ce-MnO 2 and $\mathrm{Ce}-\mathrm{MnO}_{2}-\mathrm{GNS}$.

The FTIR spectra of GO, GNS and $\mathrm{Ce}-\mathrm{MnO}_{2}-\mathrm{GNS}$ in the range of $4000-400 \mathrm{~cm}^{-1}$ are shown in Fig. 3. Almost all the characteristic peaks of GO disappear for GNS a $\square$ r chemical reduction, including the absorption peaks $\mathrm{O}-\mathrm{H}$ deformation vibrations of tertiary $\mathrm{C}-\mathrm{OH}\left(1410 \mathrm{~cm}^{-1}\right)$, O-H deformation vibrations of $\mathrm{COOH}$ groups $\left(1620 \mathrm{~cm}^{-1}\right)$, and C]O stretching vibrations of $\mathrm{COOH}$ groups $\left(1720 \mathrm{~cm}^{-1}\right) \cdot{ }^{30,31}$ In the case of $\mathrm{Ce}-\mathrm{MnO}_{2}$, the typical characteristic peak of lower wavenumber at $574 \mathrm{~cm}^{-1}$ can be clearly observed, which is commonly attributed to the $\mathrm{Mn}-\mathrm{O}$ vibrations of the $\left[\mathrm{MnO}_{6}\right]$ octahedral. ${ }^{32,33}$ After the electrostatic assembly of GNS and $\mathrm{Ce}-\mathrm{MnO}_{2}$, compared with GNS, the bands assigned to the Mn-O stretching vibration at $574 \mathrm{~cm}^{-1}$ still exist, ${ }^{32,33}$ and several additional absorption bands at 1040,1128, and $1620 \mathrm{~cm}^{-1}$ were present, attributed to the $\mathrm{Si}-\mathrm{O}-\mathrm{Si}, \mathrm{Si}-\mathrm{OMn}$, and $\mathrm{N}-\mathrm{H}$ stretching or bending vibrations, respectively. ${ }^{17}$ It implies that $\mathrm{Ce}-\mathrm{MnO}_{2}$ nanoparticles are successfully loaded on the large surface of GNS during the electrostatic assembly process.

Raman scattering spectroscopy is an effective method to examine the microstructure of carbonaceous materials because of its sensitivity toward these materials. Fig. 4 shows the Raman spectra of $\mathrm{Ce}-\mathrm{MnO}_{2}, \mathrm{GO}$, GNS and $\mathrm{Ce}-\mathrm{MnO}_{2}-\mathrm{GNS}$. The Raman spectrum of the $\mathrm{Ce}-\mathrm{MnO}_{2}$ has a distinct sharp peak located at $636 \mathrm{~cm}^{-1}$, which can be attributed to the $\mathrm{Mn}-\mathrm{O}$ vibrations perpendicular to the direction of the $\mathrm{MnO}_{6}$ octahedral double chains of $\mathrm{Ce}-\mathrm{MnO}_{2} \cdot{ }^{34}$ As shown in Fig. 4, GO exhibits a Raman shift at about 1593 (G band), corresponding to the $E_{2 g}$ mode of graphite, which is related to the vibration of the $\mathrm{sp}^{2}$-bonded carbon atoms in a two-dimensional hexagonal lattice. Another dominant peak at about $1357 \mathrm{~cm}^{-1}$ (D band) is related to the defects and disorder in the hexagonal graphitic layers. ${ }^{35}$ The intensity ratio $\left(I_{\mathrm{D}} / I_{\mathrm{G}}\right)$ of the $\mathrm{D}$ to the $\mathrm{G}$ bands of the $\mathrm{GO}$ is about 1.30. Moreover, it is observed that the $I_{\mathrm{D}} / I_{\mathrm{G}}$ of GNS increased to 1.69. After electrostatic interaction between $\mathrm{Ce}-\mathrm{MnO}_{2}$ and $\mathrm{GNS}$, Ce- $\mathrm{MnO}_{2}-\mathrm{GNS}$ shows a higher $I_{\mathrm{D}} / I_{\mathrm{G}}$ ratio value than GNS due to the decrease in the ordered graphitic structure after the attachment of $\mathrm{Ce}-\mathrm{MnO}_{2}$. In addition, the peak at about $636 \mathrm{~cm}^{-1}$ corresponding to the $\mathrm{Mn}-\mathrm{O}$ stretching mode is still observed in the Raman spectrum of $\mathrm{Ce}-\mathrm{MnO}_{2}-\mathrm{GNS}$. The results of XRD, EDS, FTIR and Raman spectra further indicate that the hybrid structure composed of GNS and $\mathrm{Ce}-\mathrm{MnO}_{2}$ was successfully synthesized..$^{36,37}$

XPS analysis was used to investigate the surface composition and oxidation state of the $\mathrm{Ce}-\mathrm{MnO}_{2}-\mathrm{GNS}$ hybrid. In Fig. 5A, it can be seen that the product contains $\mathrm{C}, \mathrm{O}, \mathrm{Si}, \mathrm{N}, \mathrm{Mn}$ and $\mathrm{Ce}$ elements. The high resolution $\mathrm{C} 1$ s peak of the $\mathrm{Ce}-\mathrm{MnO}_{2}-\mathrm{GNS}$ hybrid can be deconvoluted into four components corresponding to carbon atoms in different functional groups: the graphitic C-C group (284.6 eV), C-O-C group (286.3 eV), C-OH

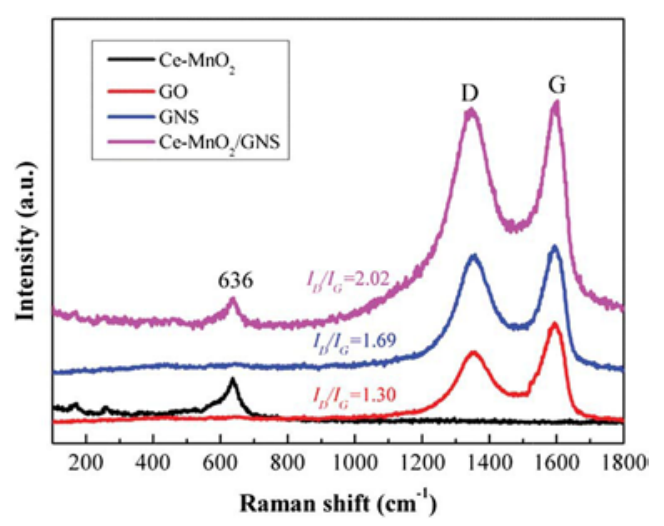

Fig. 4 Raman spectra of $\mathrm{Ce}-\mathrm{MnO}_{2}, \mathrm{GO}, \mathrm{GNS}$ and $\mathrm{Ce}-\mathrm{MnO}_{2}-\mathrm{GNS}$. 
group (285.3 eV) and carboxyl C]O group (288.4 eV). ${ }^{26,38}$ Two peaks corresponding to $M n 2 \mathrm{p}_{3 / 2}$ and $M{ }^{2} \mathrm{p}_{1 / 2}$ are located at $642.2 \mathrm{eV}$ and $654.4 \mathrm{eV}$, respectively. ${ }^{34}$ The Ce3d spectrum of the $\mathrm{Ce}-\mathrm{MnO}_{2}-\mathrm{GNS}$ hybrid shown in Fig. 5 is composed of individual overlapping peaks, which are resolved into two sets of spin-orbital multiplets $3 d_{5 / 2}-3 d_{3 / 2}$. The feature of $v, v ", v "$ '” $u$, u", u", corresponding to the Ce in $4+$ oxidation state, while the presence of $v^{\prime}$ and $u^{\prime}$ demonstrates the presence of Ce in $3+$ oxidation state. In this work, the peaks at 882.5, 888.4 and 898.5 $\mathrm{eV}$ are assigned to the $\mathrm{v}, \mathrm{v}$ " and $\mathrm{v}$ "' of $\mathrm{Ce} 3 \mathrm{~d}_{5 / 2}$, and the peaks at 901.2, 906.9 and $916.3 \mathrm{eV}$ are observed for u, u" and u"' of $\mathrm{Ce}_{3} \mathrm{~d}_{3 / 2}$. The presence of $\mathrm{Ce}^{3+}$ in the hybrid is confirmed by the appearance of weak signals at 886.7 (v') and $904.8 \mathrm{eV}$ (u'). ${ }^{39,40}$

TGA measurements were used to investigate the influence of $\mathrm{Ce}-\mathrm{MnO}_{2}$ on the thermal stability of GNS. Fig. 6 gives the TGA curves of $\mathrm{Ce}-\mathrm{MnO}_{2}$, GNS and $\mathrm{Ce}-\mathrm{MnO}_{2}-\mathrm{GNS}$ hybrid performed up to $800{ }^{\circ} \mathrm{C}$ under air at a heating rate of $20{ }^{\circ} \mathrm{C} \mathrm{min}^{-1}$. Ce$\mathrm{MnO}_{2}$ displays a maximum weight loss of about $4 \%$ at
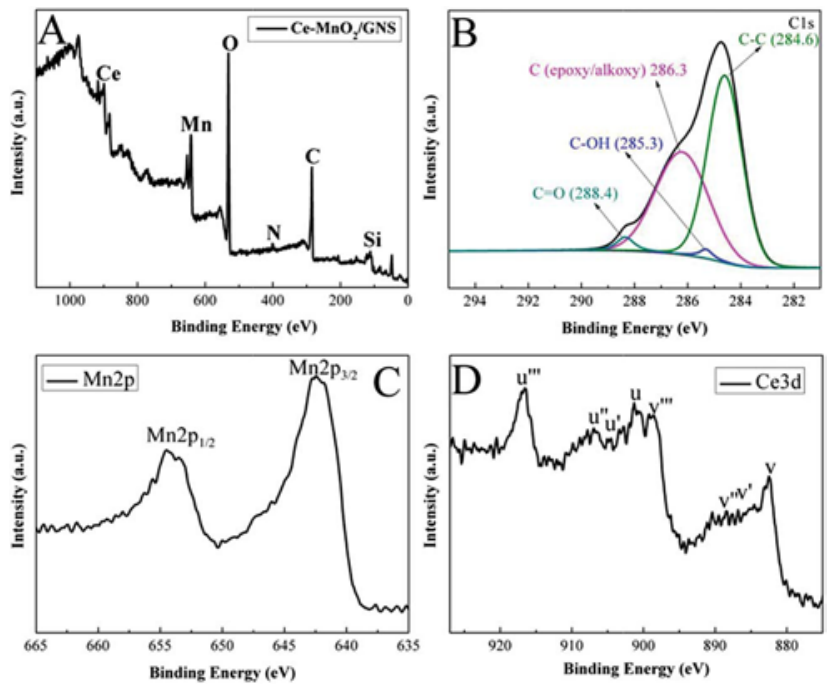

Fig. 5 XPS spectra of the Ce- $\mathrm{MnO}_{2}-\mathrm{GNS}$ hybrid (A), C1s (B), Mn2p (C) and Ce3d (D).

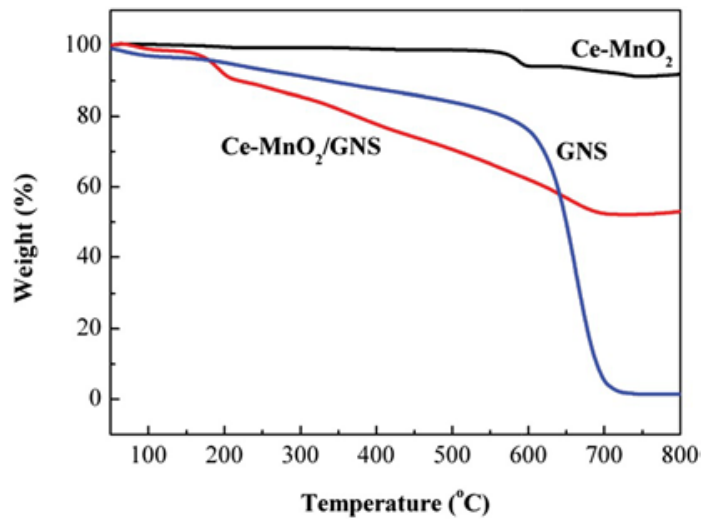

Fig. 6 TGA thermograms of $\mathrm{GNS}, \mathrm{Ce}-\mathrm{MnO}_{2}$ and $\mathrm{Ce}-\mathrm{MnO}_{2}-\mathrm{GNS}$ in an air atmosphere. around $587^{\circ} \mathrm{C}$, corresponding to the loss of oxygen from $\mathrm{MnO}_{2}$ lattice and resulting in the phase transformation to $\mathrm{Mn}_{2} \mathrm{O}_{3}$. Pure GNS shows a consecutive mass loss with a weight loss of about $97.5 \mathrm{wt} \%$, which should be attributed to the removal of carbon skeleton by burning of GNS. ${ }^{41}$ In contrast, the resulting $\mathrm{Ce}-\mathrm{MnO}_{2}-\mathrm{GNS}$ hybrid exhibits remarkably different thermogravimetric behavior with about $52 \mathrm{wt} \%$ of residue at $800{ }^{\circ} \mathrm{C}$. These results demonstrate that the combination of $\mathrm{Ce}-\mathrm{MnO}_{2}$ with GNS significantly improves the residue yield of GNS.

\subsection{Thermal and fire properties of EP and its nanocomposites}

The thermal stability of the EP and its nanocomposites was evaluated by TGA, and derivative thermogravimetric (DTG) curves were generated. As shown in Fig. 7, all the nanocomposites presented degradation behaviors similar to that of pure EP, and the main difference is degradation temperatures. The thermal degradation process of pure EP mainly consists of two stages based on the TGA profile, which mainly correspond to the decomposition of the macromolecular chains in the temperature range of $350-480{ }^{\circ} \mathrm{C}$ and further thermal oxidation of char residue beyond $500{ }^{\circ} \mathrm{C}$. The $T_{-5 \%}$ and $T_{-50 \%}$ are defined as the temperatures where $5 \%$ and $50 \%$ weight losses occur, while $T_{\max }$ is defined as the maximum decomposition temperature. The data are listed in Table 1 . In comparison with neat $\mathrm{EP}$, the $T_{-5 \%}, T_{-50 \%}$ and $T_{\max }$ of $\mathrm{Ce}-\mathrm{MnO}_{2}-\mathrm{EP}$ nanocomposite were decreased because of the catalytic degradation of $\mathrm{Ce}-\mathrm{MnO}_{2}{ }^{42}$ After introducing GNS into the EP matrix, the $T_{-5 \%}$, $T_{-50 \%}$ and $T_{\max }$ were slightly lower than that of the pure EP, which is attributed to the high heat conductivity of GNS. ${ }^{43}$ However, it is found that the $\mathrm{Ce}-\mathrm{MnO}_{2}-\mathrm{GNS}-\mathrm{EP}$ nanocomposite demonstrates improved thermal stability with $4.6^{\circ} \mathrm{C}, 8.8^{\circ} \mathrm{C}$ and $8.9{ }^{\circ} \mathrm{C}$ increments for $T_{-5 \%}, T_{-50 \%}$ and $T_{\max }$, respectively, as compared to those of pure EP. As far as the char yield is concerned, the char residue at $700{ }^{\circ} \mathrm{C}$ is significantly increased
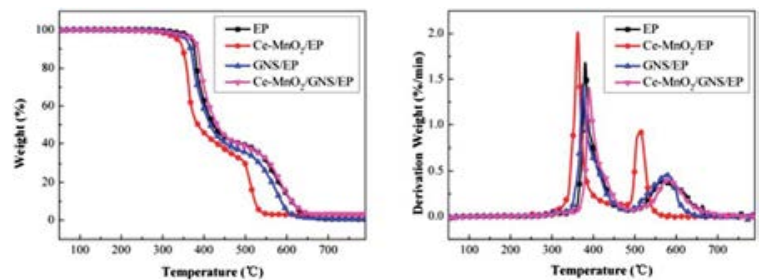

Fig. 7 TGA and DTA curves of pure EP, GNS-EP, Ce-MnO ${ }_{2}-E P, C e-$ $\mathrm{MnO}_{2}$-GNS-EP.

Table 1 TGA data for EP and its nanocomposites in air

\begin{tabular}{lllll}
\hline Sample & $T_{-5 \%}\left({ }^{\circ} \mathrm{C}\right)$ & $T_{-50 \%}\left({ }^{\circ} \mathrm{C}\right)$ & $T_{\max }\left({ }^{\circ} \mathrm{C}\right)$ & $\begin{array}{l}\text { Char residue } \\
\text { at } 700{ }^{\circ} \mathrm{C}\end{array}$ \\
\hline $\mathrm{EP}$ & 369.6 & 422.7 & 380.3 & 0.6 \\
$\mathrm{Ce}-\mathrm{MnO}_{2}$-EP & 335.8 & 384.9 & 362.2 & 3.0 \\
$\mathrm{GNS}-\mathrm{EP}$ & 356.6 & 414.7 & 374.6 & 0.4 \\
$\mathrm{Ce}-\mathrm{MnO}_{2}$-GNS-EP & 374.2 & 431.5 & 389.2 & 3.4
\end{tabular}



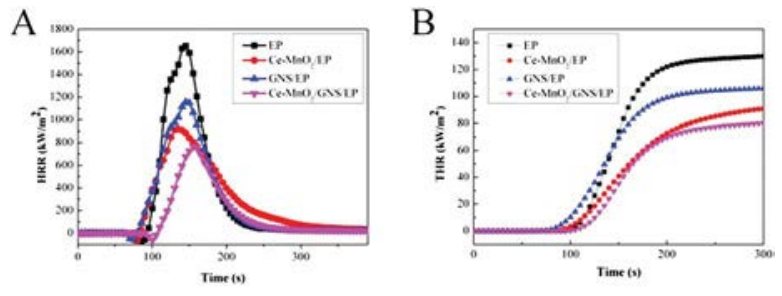

$\mathrm{C}$

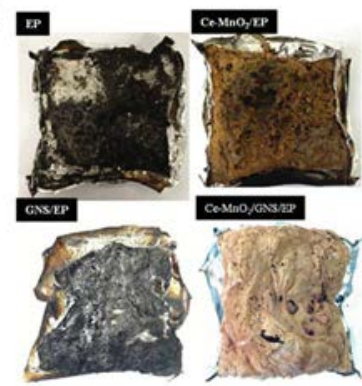

Fig. 8 HRR (A), THR (B) curves and digital photos (C) of char for EP and its nanocomposites obtained from a cone calorimetry test.

when $\mathrm{Ce}-\mathrm{MnO}_{2}$ or $\mathrm{Ce}-\mathrm{MnO}_{2}-\mathrm{GNS}$ was added due to the catalytic carbonization of $\mathrm{Ce}-\mathrm{MnO}_{2}{ }^{44}$ The improved char yield provides a protective shield to mass and heat transfer between air and polymeric materials, and reduces the heat release rate during combustion. ${ }^{19}$ From the DTG curves (Fig. 7), it can be clearly seen that the addition of $\mathrm{Ce}-\mathrm{MnO}_{2}-\mathrm{GNS}$ or GNS notably decreases the maximum mass loss rate (the peak of DTG curves) compared to that of pure EP, implying the mass barrier effect of GNS. ${ }^{45}$

Cone calorimetry is a widely used method for measuring the flammability of various materials in real-world fire. ${ }^{46}$ The heat release rate (HRR) and peak heat release rate (THR) curves for $\mathrm{EP}$ and its nanocomposites are shown in Fig. 8A and B, and some important parameters obtained from the cone calorimeter tests, such as the peak heat release rate (pHRR), THR, total smoke release (TSR) and the average mass loss rate (AMLR), are also tabulated in Table 2. It is shown that neat EP burns extremely rapidly after ignition and the pHRR value reaches $1653 \mathrm{~kW} \mathrm{~m}^{-2}$. GNS is usually used to impart flame retardant properties to polymers due to its unique 2D nanosheet structure. ${ }^{43,47}$ As expected, incorporating GNS into EP decreases pHRR to $1156 \mathrm{~kW} \mathrm{~m}^{-2}$. For Ce- $\mathrm{MnO}_{2}-\mathrm{EP}$, the $\mathrm{pHRR}$ decreases to $920 \mathrm{~kW} \mathrm{~m}^{-2}$. In addition, the pHRR of $\mathrm{Ce}-\mathrm{MnO}_{2}-\mathrm{GNS}-\mathrm{EP}$ shows further reduction compared with that of both GNS-EP and $\mathrm{Ce}-\mathrm{MnO}_{2}-\mathrm{EP}$. In addition, the THR values of GNS-EP, $\mathrm{Ce}-\mathrm{MnO}_{2}-\mathrm{EP}$ and $\mathrm{Ce}-\mathrm{MnO}_{2}-\mathrm{GNS}-\mathrm{EP}$ are significantly reduced by $17 \%, 26 \%$ and $35 \%$, respectively, compared to that of pristine EP. Fig. 8C shows the digital photographs of the residual chars after cone calorimeter tests of EP and its nanocomposites. As can be seen, neat EP almost does not form a char while the GNS-EP and $\mathrm{Ce}-\mathrm{MnO}_{2}-\mathrm{EP}$ nanocomposites form char with many holes and cracks. The addition of $\mathrm{Ce}-\mathrm{MnO}_{2}-\mathrm{GNS}$ leads to the increase in char yield and the formation of a continuous and compact char layer, which are good in agreement with the TGA results. The continuous and compact char surfaces are good barriers to protect the underlying polymers and inhibit the exchange of degradation products, combustible gases and oxygen ${ }^{48,49}$ The results of flammability exhibit that Ce$\mathrm{MnO}_{2}$-GNS-EP nanocomposite show the best flame retardancy among EP nanocomposites. By combining TGA and cone calorimetry results, it is reasonably believed that some epoxy chains participated in the carbonization process due to the barrier effect of GNS and the catalysis of $\mathrm{Ce}-\mathrm{MnO}_{2}$, and more and better chars are formed, which decrease the flammability of EP nanocomposites.
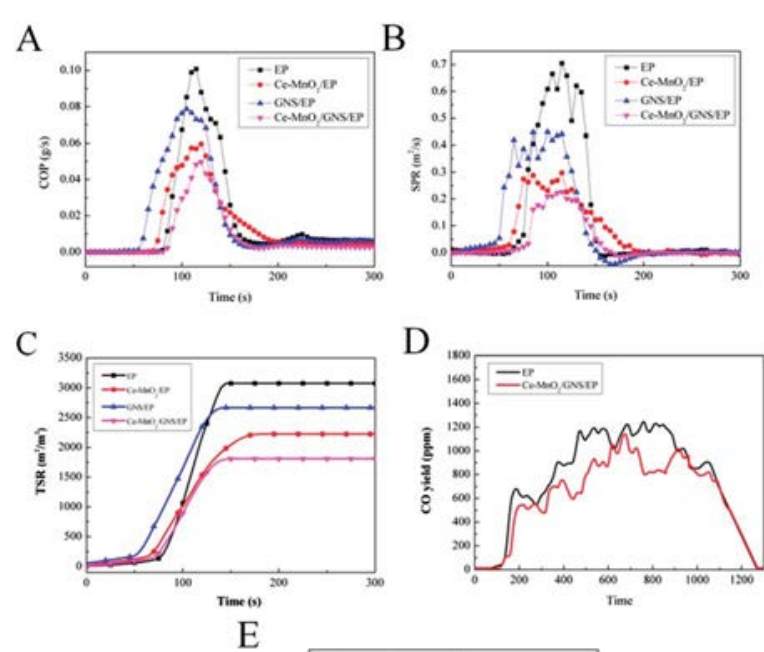

D
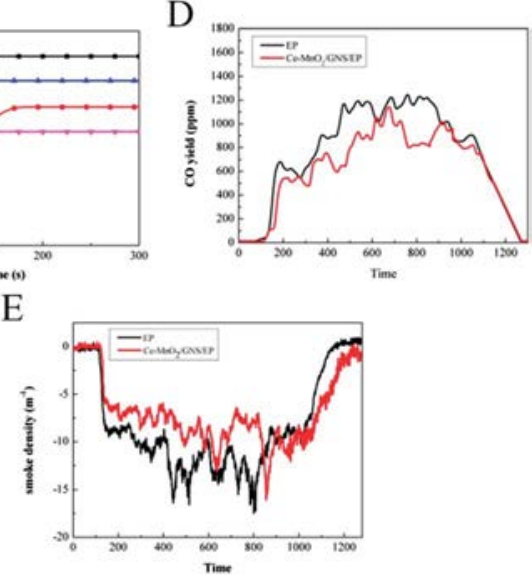

Fig. 9 CO release (A), SPR (B) and TSR (C) curves for EP and its composites obtained from cone calorimetry test; and the CO yield (D) and the smoke density $(\mathrm{E})$ versus time curves of $\mathrm{EP}$ and $\mathrm{Ce}-\mathrm{MnO}_{2}-$ GNS-EP obtained from SSTF.

Table 2 Cone calorimetry data of EP, GNS-EP, Ce- $\mathrm{MnO}_{2}-\mathrm{EP}$ and $\mathrm{Ce}-\mathrm{MnO}_{2}-\mathrm{GNS}-\mathrm{EP}$ composites

\begin{tabular}{lcccc}
\hline Sample & pHRR $\left(\mathrm{kW} \mathrm{m}^{-2}\right)$ & THR $\left(\mathrm{MJ} \mathrm{m}^{-2}\right)$ & TSR $\left(\mathrm{m}^{2} \mathrm{~m}^{-2}\right)$ & AMLR $\left(\mathrm{g} \mathrm{s}^{-1}\right)$ \\
\hline EP & $1653 \pm 58$ & $129.9 \pm 3.4$ & $3075 \pm 55$ & $0.249 \pm 0.01$ \\
GNS-EP & $1156 \pm 30$ & $107.8 \pm 2.2$ & $2666 \pm 28$ & $0.175 \pm 0.007$ \\
$\mathrm{Ce}-\mathrm{MnO}_{2}$-EP & $920 \pm 27$ & $96.7 \pm 1.8$ & $2222 \pm 19$ & $0.124 \pm 0.005$ \\
$\mathrm{Ce}^{-\mathrm{MnO}_{2}}$-GNS-EP & $765 \pm 25$ & $83.8 \pm 1.5$ & $1809 \pm 17$
\end{tabular}




\subsection{Smoke suppression properties}

EP with aromatic and aliphatic chains, which decompose to yield predominantly aromatic hydrocarbons, produces very large amounts of smoke and toxic gases. It is well-known that in most cases the real killer in fires is not the heat of the fire itself but the smoke and toxic gases. Therefore, reduction of smoke and toxic gases (especially carbon monoxide) will be beneficial to fire rescue when a fire accident occurs. Fig. 9A presents CO release curves for EP and its nanocomposites, which are obtained from cone calorimetry tests. As can be observed, CO concentration for the samples with GNS, Ce- $\mathrm{MnO}_{2}$, or $\mathrm{Ce}-\mathrm{MnO}_{2}-\mathrm{GNS}$ is significantly less than that of pure EP. AMLR is recognized to be the primary parameter responsible for influencing the HRR and the smoke production rate (SPR) of a material during combustion. ${ }^{50}$ The data contained in Table 2 clearly demonstrate that the addition of GNS, $\mathrm{Ce}-\mathrm{MnO}_{2}$, or $\mathrm{Ce}-\mathrm{MnO}_{2}-\mathrm{GNS}$ decreases the AMLR, especially for Ce$\mathrm{MnO}_{2}-\mathrm{GNS}-\mathrm{EP}$, which implies that the SPR of the EP nanocomposites during burning will be obviously reduced. The SPR curves of the samples are shown in Fig. 9B. It can be clearly seen that the maximum of SPR for $\mathrm{Ce}-\mathrm{MnO}_{2}-\mathrm{GNS}-\mathrm{EP}$ nanocomposite is the lowest among all the samples. Meanwhile, TSR obtained from cone calorimetry tests was also employed to evaluate smoke yield during the combustion. As shown in

Fig. 9C, the incorporation of GNS, Ce- $\mathrm{MnO}_{2}$, or $\mathrm{Ce}-\mathrm{MnO}_{2}-\mathrm{GNS}$ reduces the TSR compared to pure EP. Among these, the $\mathrm{Ce}-\mathrm{MnO}_{2}-\mathrm{GNS}$ hybrid exhibits the best smoke suppression on EP with up to a $41.2 \%$ reduction in TSR. The ISO-TS 19700 SSTF is designed to measure the yields of combustion products, and, in particular, toxic combustion products occurring in full-scale compartment fires (Scheme 1). The CO yield and the smoke density versus time curves for the EP and $\mathrm{Ce}-\mathrm{MnO}_{2}-\mathrm{GNS}-\mathrm{EP}$ nanocomposite, which were obtained from SSTF are depicted in Fig. 9D and E. Ce-MnO $2-$ GNS-EP also exhibits a reduced CO concentration and smoke density compared to those of pure EP.

To investigate the influence of $\mathrm{Ce}-\mathrm{MnO}_{2}-\mathrm{GNS}$ on the evolved gaseous volatiles during pyrolysis, the volatile components released from EP and its composites were monitored by a TG-IR technique. FTIR spectra obtained at the maximum evolution

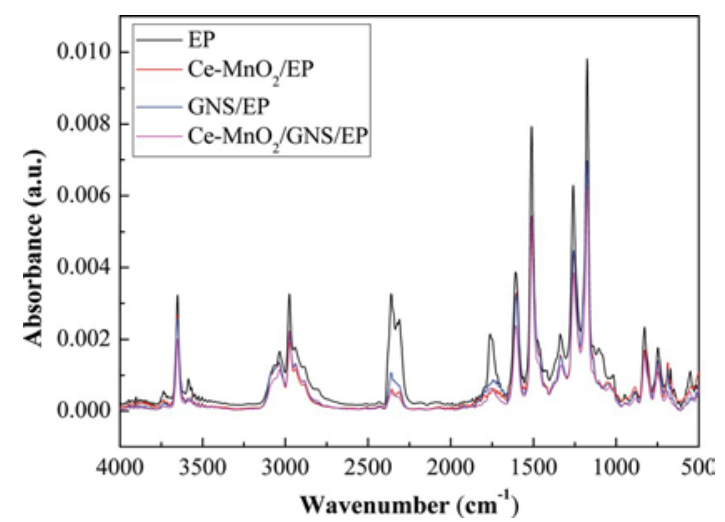

Fig. 10 IR spectra of gasified pyrolysis products for pure EP and its composites at the maximum evolution rate. rate during the thermal decomposition of EP and its nanocomposite are shown in Fig. 10. Some small molecular gaseous decomposition products evolved from EP and its nanocomposite are identified unambiguously by characteristic strong FTIR signals, such as -C-H groups for allyl alcohol, acetone, ethers and various hydrocarbons (3100-2800 $\mathrm{cm}^{-}$), $\mathrm{CO}_{2}\left(2360 \mathrm{~cm}^{-1}\right)$, CO $\left(2180 \mathrm{~cm}^{-1}\right)$ and aromatic compounds (1605, 1510 and $\left.1460 \mathrm{~cm}^{-1}\right) .^{51}$ Typical thermal degradation products of EP nanocomposites that are similar to those of pure EP are observed. To provide a clear comparison, the intensities of typical gaseous volatiles for pure EP and its nanocomposite are presented in Fig. 11. With the incorporation of inorganic additives, the intensity of gas emission is shifted to lower values. Moreover, it can be obviously observed that the addition of $\mathrm{Ce}-\mathrm{MnO}_{2}-\mathrm{GNS}$ significantly decreased the evolution of all the evolved compounds and showed the best smoke suppression performance among all the nanocomposites.

The possible reasons for the reduced smoke and gases toxicity of $\mathrm{Ce}-\mathrm{MnO}_{2}-\mathrm{GNS}-\mathrm{EP}$ are illustrated as follows. From the TGA results (Fig. 7), the synergistic effect between GNS and $\mathrm{Ce}-\mathrm{MnO}_{2}$ can promote char formation in the EP nanocomposite, which implies that there is more compact char residue formed on the surface of the sample with $\mathrm{Ce}^{-}$ $\mathrm{MnO}_{2}-\mathrm{GNS}$. In addition, the digital photographs of the residual chars (Fig. 8C) further confirm this point. The compact char residue and the physical barrier effect of GNS can restrain the release of combustible gases such that the released flammable gases can completely burn, which leads to the slow CO production rate. Metal catalysis has also been found to be an effective way to eliminate volatile organic compounds and toxic
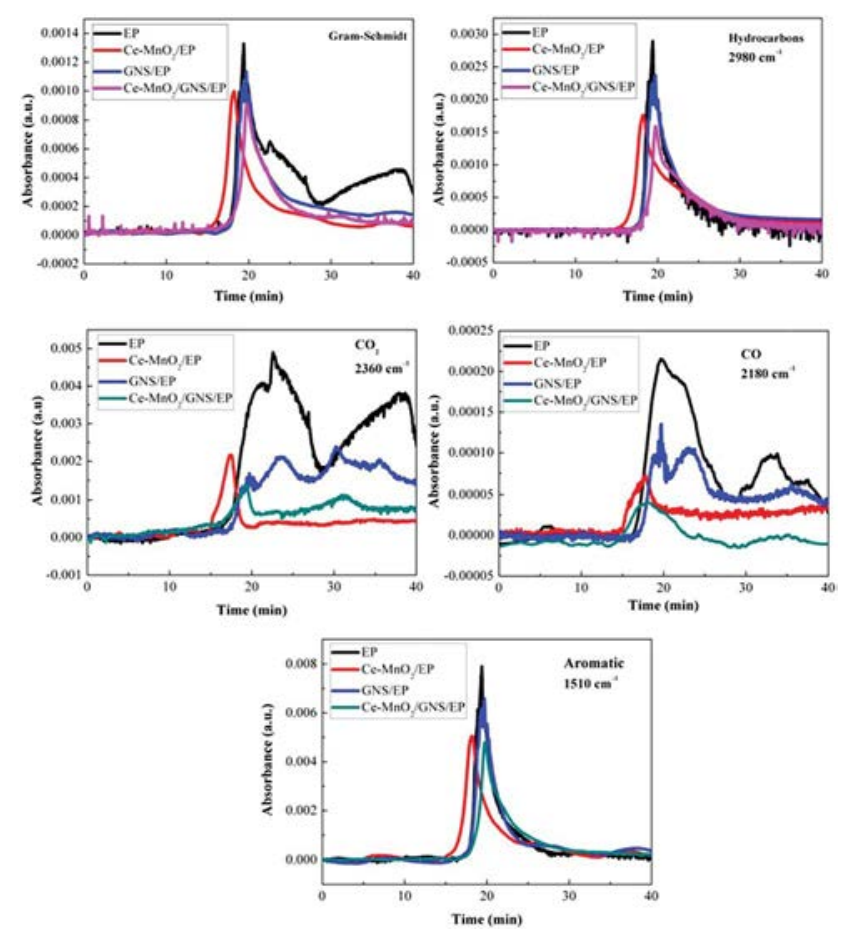

Fig. 11 Intensity of characteristic peaks for the pyrolysis products of pure EP and its composites. 
gases during combustion reactions. ${ }^{52,53}$ As an important functional metal oxide, $\mathrm{MnO}_{2}$ has exciting catalytic effects due to its distinctive physical and chemical properties. Zhang et al. reported that manganese oxides are promising catalyst in $\mathrm{CO}$ oxidation. ${ }^{54} \mathrm{Li}$ et al. demonstrated that the $\mathrm{MnO}_{2}$ microspheres showed a higher catalytic ability for the catalytic elimination of benzene. ${ }^{55}$ Moreover, the presence of cerium can improve the oxygen storage capacity of the catalyst through the transformation between $\mathrm{Ce}^{4+}$ and $\mathrm{Ce}^{3+}$ under controlled conditions, which promotes the catalytic ability of the catalyst. ${ }^{56,57}$ Therefore, it is reasonable to believe that the catalytic effect of Ce$\mathrm{MnO}_{2}$ plays an important role in the elimination of volatile organic compounds and toxic gases. The reduction of the volatile organic compounds and toxic gases in the smoke and gases will be beneficial to fire rescue when an accident occurs.

\subsection{Flame retardant mechanism}

It is well-known that layered nanofillers, including layered silicate $^{58,59}$ and LDHs, ${ }^{60,61}$ play a role in the condensed phase by acting as "char reinforcers". When a condensed phase action is the main mechanism for flame retardant additives, its efficiency strongly depends on the structure and composition of the char during combustion. Therefore, investigating the properties and the microstructure of the resultant char layers provides an
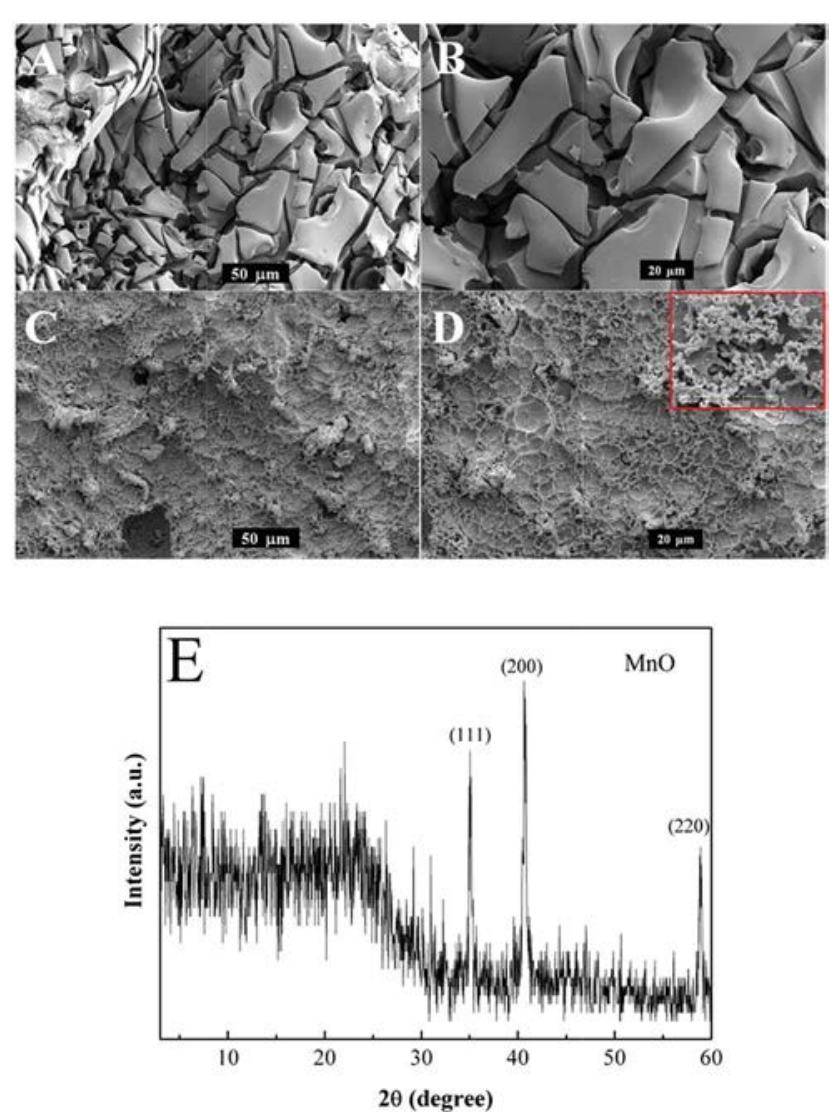

Fig. 12 SEM images (A-D) of the surface morphology of the residue of $\mathrm{EP}$ and $\mathrm{Ce}-\mathrm{MnO}_{2}-\mathrm{GNS}-\mathrm{EP}$ and XRD pattern (E) of the char residue of $\mathrm{Ce}-\mathrm{MnO}_{2}-\mathrm{GNS}-\mathrm{EP}$ nanocomposite after cone calorimetry tests. insight into understanding how the flame retardant additives act in the condensed phase. As indicated in Fig. 12A, the residual char of pure EP presents a rough and loose char layer with a mass of cracks and holes dispersed on the surface. Moreover, the char displays a porous and incompact surface with high-magnification SEM imaging (Fig. 12B). However, when $2 \mathrm{wt} \%$ of $\mathrm{Ce}-\mathrm{MnO}_{2}-\mathrm{GNS}$ is added into $\mathrm{EP}$, the cracks and holes are reduced (Fig. 12C and D) and the porous and incompact surface changes into a more compact surface. More detailed information regarding the char surface is obtained from the inset of Fig. 12D; it can be observed that the final char contains a mass of nano-sized spheres, and the char nanospheres were connected to each other to form a "macromolecular-chain" structure. The dense char layer can lower the efficiency of heat and volatiles transference because of the strong hindering effect, and can provide better flame shielding for the underlying material during combustion. ${ }^{48,49}$ The char residue of $\mathrm{Ce}-\mathrm{MnO}_{2}-\mathrm{GNS}-\mathrm{EP}$ was also characterized by its XRD pattern, as shown in Fig. 12E. The visible peaks appearing at $34.9^{\circ}, 40.6^{\circ}$ and $58.7^{\circ}$ are attributed to the diffraction of MnO (JCPDS Card no. 89-4835). It is easily understood that $\mathrm{MnO}$ nanoparticles are formed in situ via the reduction reaction of $\mathrm{MnO}_{2}$ by degraded gases from EP, which can catalyze the carbonization of degradation products. ${ }^{44}$

Fig. 13 shows the Raman spectra of the residual chars of EP, GNS-EP, Ce- $\mathrm{MnO}_{2}-\mathrm{EP}$ and $\mathrm{Ce}-\mathrm{MnO}_{2}-\mathrm{GNS}-\mathrm{EP}$ after cone calorimetry tests. As can be observed, the Raman spectra of the four samples exhibit a similar shape, with two peaks at $1593 \mathrm{~cm}^{-1}$ and $1358 \mathrm{~cm}^{-1}$. The characteristic peak at $1593 \mathrm{~cm}^{-1}$ is called G band, corresponding to the first order scattering of the $E_{2 g}$ mode of hexagonal graphite, while the other is called D band, arising from the vibration of carbon atoms with dangling bonds in the plane terminations of disordered graphite. ${ }^{62}$ The graphitization degree of the char can be estimated by $I_{\mathrm{D}} / I_{\mathrm{G}}$, where $I_{\mathrm{D}}$ and $I_{\mathrm{G}}$ are the integrated intensities of the $\mathrm{D}$ and $\mathrm{G}$ bands, respectively. Basically, the lower the ratio of $I_{\mathrm{D}} / I_{\mathrm{G}}$, the better is the structure of the char. The peak intensity ratio $I_{\mathrm{D}} / I_{\mathrm{G}}$ of GNS-EP and $\mathrm{Ce}-\mathrm{MnO}_{2}-\mathrm{EP}$ is slightly lower than that of EP, indicating the improvement of the graphitized carbons in the
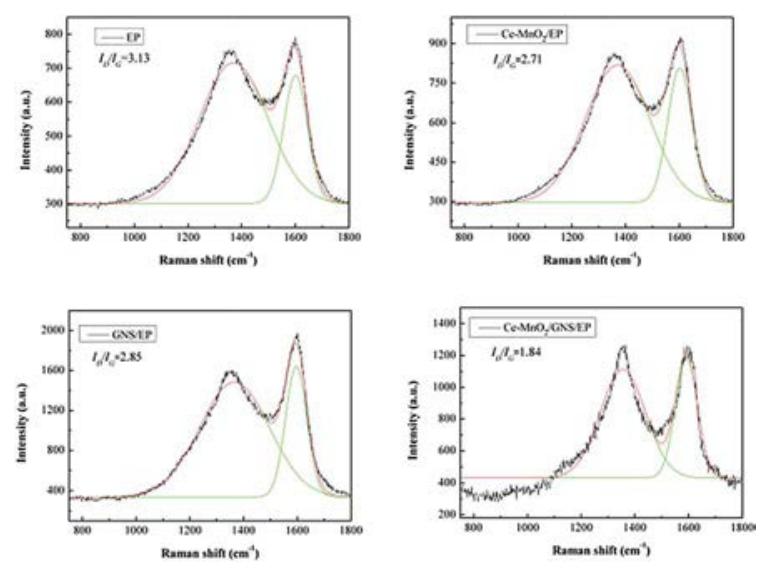

Fig. 13 Raman curves of the residue for EP and its nanocomposites. 
residual char. ${ }^{63}$ Furthermore, incorporating the $\mathrm{Ce}-\mathrm{MnO}_{2}-\mathrm{GNS}$ hybrid into EP remarkably decreases the intensity ratio $I_{\mathrm{D}} / I_{\mathrm{G}}$ compared to that of EP, suggesting a synergistic effect for char formation between $\mathrm{Ce}-\mathrm{MnO}_{2}$ and GNS. The high graphitization degree of the char is known to be compact and efficient in terms of thermal insulation, which provides a protective shield that results in a decrease in heat and mass transfers between the flame and the material. ${ }^{19}$

As is well-known, the pyrolysis products during combustion play a very important role in the flame-retardant performance of materials. To explore the flame-retardant mechanism of the EP nanocomposites, the pyrolysis products during combustion were studied by the DP-MS technique. Fig. 14 depicts the total ion current (TIC) chromatogram of EP and its nanocomposite, and EI-MS spectra corresponding to the TIC peaks with the maximum intensity. The pyrolysis fragment ions with a molecular weight of $x$ are labelled as $x_{M}$ and are identified in Fig. 15. For pure EP, a strong peak at $255 \mathrm{~m} / \mathrm{z}$ corresponds to $\mathrm{C}_{17} \mathrm{H}_{19} \mathrm{O}_{2}$. In addition, the peaks at $269 \mathrm{~m} / \mathrm{z}, 213 \mathrm{~m} / \mathrm{z}, 197 \mathrm{~m} / \mathrm{z}$ and $135 \mathrm{~m} / \mathrm{z}$ can be assigned to the pyrolysis products of $\mathrm{C}_{17} \mathrm{H}_{21} \mathrm{~N}_{2} \mathrm{O}, \mathrm{C}_{14} \mathrm{H}_{13} \mathrm{O}_{2}, \mathrm{C}_{15} \mathrm{H}_{18}$, and $\mathrm{C}_{9} \mathrm{H}_{11} \mathrm{O}$, respectively. Moreover, some fragment ions recombine to form some new products under high temperature environments; for instance, the recombination between benzene and aniline generates

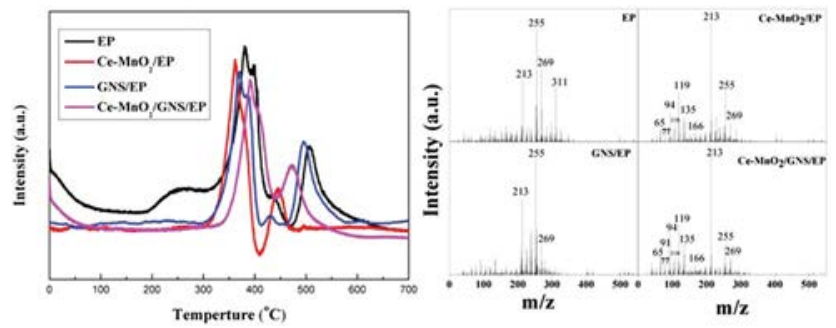

Fig. 14 Total ion current (TIC) curves of the decomposition process of EP and its composites, and EI-MS spectra of compounds evolved from $\mathrm{EP}$ and its composites at the peak maximum in the TIC curves.

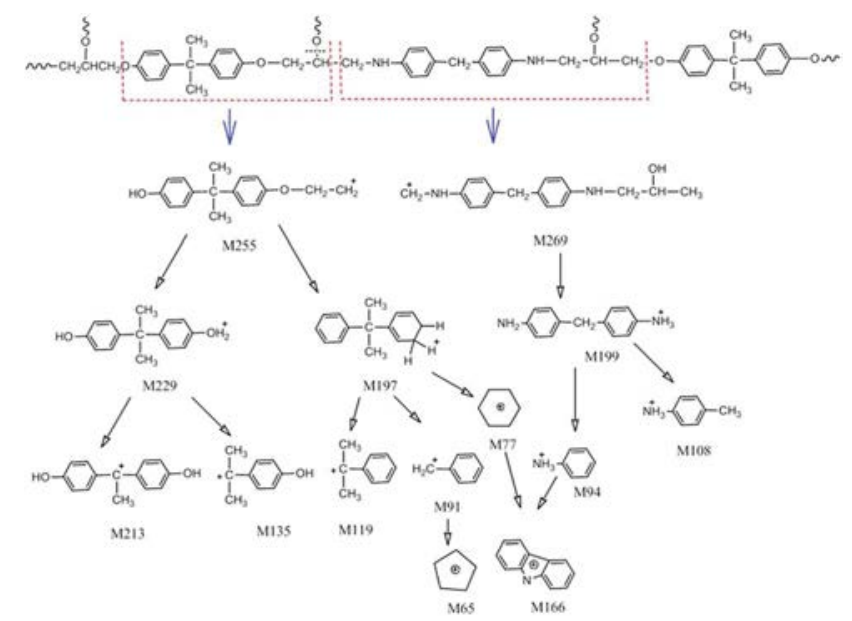

Fig. 15 Simplified mass fragmentations of the Ce-MnO ${ }_{2}-$ GNS-EP nanocomposite.

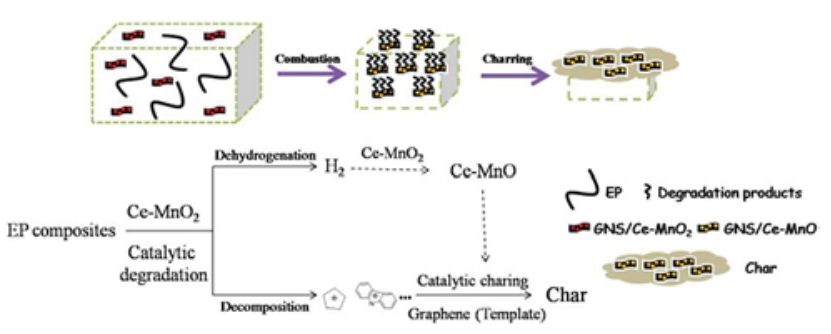

Scheme 2 Illustration for the flame-retardant mechanism for the combination effect of the Ce- $\mathrm{MnO}_{2}-\mathrm{GNS}$ hybrid.

carbazole $(166 \mathrm{~m} / \mathrm{z})$, and the carbazole and benzene reconstitute to produce a few polycyclic aromatic hydrocarbons $(497 \mathrm{~m} / \mathrm{z})$. The spectrum of the GNS-EP composite shows similar pyrolysis products as that of EP. In contrast, the main fractions in the degradation products of the $\mathrm{Ce}-\mathrm{MnO}_{2}-\mathrm{GNS}-\mathrm{EP}$ or $\mathrm{Ce}-\mathrm{MnO}_{2}$ includes $\mathrm{C}_{14} \mathrm{H}_{13} \mathrm{O}_{2}(213 \mathrm{~m} / \mathrm{z})$, which is with lower carbon numbers than that of neat EP or GNS-EP. In fact, it has been previously reported in the literature that solid acids can catalyze the degradation of polymers, which results in the formation of pyrolysis products with lower carbon numbers, and the degradation products with lower carbon numbers could easily catalyze carbonization in the presence of metal oxides. ${ }^{64,65}$ Manganese oxides have been reported to be the most efficient solid acid for suppressing the recombination of macromolecular hydrocarbon radicals due to the presence of several acidic sites. ${ }^{42,66}$ In this work, carbon numbers of pyrolysis products from the $\mathrm{Ce}-\mathrm{MnO}_{2}-\mathrm{GNS}-\mathrm{EP}$ composite also decreased compared with that of EP. Thus, this undoubtedly results from the catalytic degradation effect for EP by Ce- $\mathrm{MnO}_{2} \cdot{ }^{42,66}$ Moreover, degradation products with lower carbon numbers could extend the contacting time of with metal oxides catalyst under the physical barrier effect of GNS. With $\mathrm{MnO}_{2}$ catalyst, Hong et al. used a simple method to synthesize multi-layer graphene flakes from pyrolyzing biodegradable poly(butylene succinate) composites. ${ }^{44}$ Thus, it is reasonably believed that the improved fire resistant properties of the $\mathrm{Ce}-\mathrm{MnO}_{2}-\mathrm{GNS}-\mathrm{EP}$ nanocomposite are attributed to the synergism of the catalytic effect of $\mathrm{Ce}-\mathrm{MnO}_{2}$ and the physical barrier effect of GNS. In view of the results of volatile pyrolysis fragment ions, the mechanism for the improved fire resistant properties of the $\mathrm{Ce}-\mathrm{MnO}_{2}-\mathrm{GNS}-\mathrm{EP}$ nanocomposite is illustrated in Scheme 2. During the combustion process, $\mathrm{Ce}-\mathrm{MnO}_{2}$ with catalytic activity leads to the formation of pyrolysis products with lower carbon numbers, which can be easily catalyzed for carbonization in the presence of metal oxides. Meanwhile, $\mathrm{Ce}-\mathrm{MnO}_{2}$ is reduced in situ to Ce-MnO by reductive hydrocarbons through redox reactions, which can catalyze the carbonization of degradation products. ${ }^{44}$ Moreover, GNS acts as a physical barrier, which can absorb degraded products to extend contact time with metal oxides catalyst, and continually propagate on the GNS, which serves as a template of micro-char. Furthermore, the degraded products are dehydrogenated and catalytically converted into char by the combination of the GNS physical barrier effect and $\mathrm{Ce}-\mathrm{MnO}_{2}$ catalysis effect. 


\section{Conclusions}

In conclusion, $\mathrm{Ce}-\mathrm{MnO}_{2}-\mathrm{GNS}$ hybrid was successfully prepared through electrostatic interactions between $\mathrm{Ce}-\mathrm{MnO}_{2}$ and $\mathrm{GNS}$, and the composition and structure were confirmed by XRD, EDS and XPS. TGA investigation revealed that the modification of GNS with $\mathrm{Ce}-\mathrm{MnO}_{2}$ could enhance the residue yield of GNS compared with pure GNS. The incorporation of $2 \mathrm{wt} \% \mathrm{Ce}-$ $\mathrm{MnO}_{2}-\mathrm{GNS}$ hybrid into EP led to the improvement of degradation temperatures, char residue and DTG peak value compared to that of pure EP. Meanwhile, the pHRR and THR values of $\mathrm{Ce}-\mathrm{MnO}_{2}-\mathrm{GNS}-\mathrm{EP}$ were significantly reduced compared to those of neat EP. Moreover, the amount of organic volatiles released during the combustion of EP was significantly reduced and toxic $\mathrm{CO}$ was suppressed after incorporating $\mathrm{Ce}^{-}$ $\mathrm{MnO}_{2}-\mathrm{GNS}$. The notable reduction of fire hazards was mainly attributed to the synergistic action between physical barrier effect of GNS and the catalytic effect of $\mathrm{Ce}-\mathrm{MnO}_{2} \cdot \mathrm{Ce}-\mathrm{MnO}_{2}$ with catalytic activity resulted in the formation of pyrolysis products with lower carbon numbers, which can easily catalyze carbonization in the presence of metal oxides. GNS acted as physical barriers, which can absorb degraded products to extend the contact time with metal oxides catalyst, and continually propagate on the GNS, which serves as a template of micro-char, while pyrolysis fragments with lower carbon numbers could easily catalyze carbonization in the presence of $\mathrm{Ce}-\mathrm{MnO}_{2}$.

\section{Acknowledgements}

The work was financially supported by the National Natural Science Foundation of China (21374111), the National Basic Research Program of China(973Program)(2012CB719701), and the National Natural Science Foundation of China (51303165).

\section{Notes and references}

1 Z. Matusinovic and C. A. Wilkie, J. Mater. Chem., 2012, 22, 18701-18704.

2 S. Pavlidou and C. D. Papaspyrides, Prog. Polym. Sci., 2008, 33, 1119-1198.

3 A. M. Beese, S. Sarkar, A. Nair, M. Naraghi, Z. An, A. Moravsky, R. O. Loutfy, M. J. Buehler, S. T. Nguyen and H. D. Espinosa, ACS Nano, 2013, 7, 3434-3446.

4 K. S. Novoselov, A. K. Geim, S. V. Morozov, D. Jiang, Y. Zhang, S. V. Dubonos, I. V. Grigorieva and A. A. Firsov, Science, 2004, 306, 666-669.

5 S. Stankovich, D. A. Dikin, G. H. B. Dommett, K. M. Kohlhaas, E. J. Zimney, E. A. Stach, R. D. Piner, S. T. Nguyen and R. S. Ruoff, Nature, 2006, 442, 282-286.

6 X. Wang, L. J. Zhi and K. Mullen, Nano Lett., 2008, 8, 323-327. 7 Y. M. Shi and L. J. Li, J. Mater. Chem., 2011, 21, 3277-3279.

8 S. P. Zhang and H. O. Song, Chem. Res. Chin. Univ., 2012, 33, 1214-1219.

9 F. Kim, J. Y. Luo, R. Cruz-Silva, L. J. Cote, K. Sohn and J. X. Huang, Adv. Funct. Mater., 2010, 20, 2867-2873.
10 G. B. Huang, J. G. Yang, J. R. Gao and X. Wang, Ind. Eng. Chem. Res., 2012, 51, 12355-12366.

11 S. H. Liao, P. L. Liu, M. C. Hsiao, C. C. Teng, C. A. Wang, M. D. Ger and C. L. Chiang, Ind. Eng. Chem. Res., 2012, 51, 4573-4581.

12 X. Wang, L. Song, H. Y. Yang, H. D. Lu and Y. Hu, Ind. Eng. Chem. Res., 2011, 50, 5376-5383.

13 X. Wang, Y. Hu, L. Song, H. Y. Yang, B. Yu, B. Kandola and D. Deli, Thermochim. Acta, 2012, 543, 156-164.

14 F. Schurz, J. M. Bauchert, T. Merker, T. Schleid, H. Hasse and R. Glaser, Appl. Catal., A, 2009, 355, 42-49.

15 R. X. Chen, J. G. Yu and W. Xiao, J. Mater. Chem. A, 2013, 1, 11682-11690.

16 M. Lewin and M. Endo, Polym. Adv. Technol., 2003, 14, 3-11. 17 Y. Liu, Z. H. Cao, Y. Zhang and Z. P. Fang, Ind. Eng. Chem. Res., 2013, 52, 5334-5340.

18 T. Tang, X. C. Chen, H. Chen, X. Y. Meng, Z. W. Jiang and W. G. Bi, Chem. Mater., 2005, 17, 2799-2802.

19 H. Yu, J. Liu, Z. Wang, Z. W. Jiang and T. Tang, J. Phys. Chem. C, 2009, 113, 13092-13097.

20 B. Schartel, R. Kunze, D. Neubert and A. Tidjani, Polym. Int, 2002, 51, 213-222.

21 Y. X. Xu and G. Q. Shi, J. Mater. Chem., 2011, 21, 3311-3323.

22 Z. P. Li, J. Q. Wang, X. H. Liu, S. Liu, J. F. Ou and S. R. Yang, J. Mater. Chem., 2011, 21, 3397-3403.

23 L. Wang, D. Wang, X. Y. Dong, Z. J. Zhang, X. F. Pei, X. J. Chen, B. A. Chen and J. A. Jin, Chem. Commun., 2011, 47, 3556-3558.

24 J. T. Zhang, J. W. Jiang and X. S. Zhao, J. Phys. Chem. C, 2011, $115,6448-6454$.

25 W. S. Hummers and R. E. Offeman, J. Am. Chem. Soc., 1958, 80, 1339.

26 S. Stankovich, D. A. Dikin, R. D. Piner, K. A. Kohlhaas, A. Kleinhammes, Y. Jia, Y. Wu, S. T. Nguyen and R. S. Ruoff, Carbon, 2007, 45, 1558-1565.

27 J. Y. Zhu and J. H. He, ACS Appl. Mater. Interfaces, 2012, 4, 1770-1776.

28 C. Xu, X. Wang and J. W. Zhu, J. Phys. Chem. C, 2008, 112, 19841-19845.

29 Y. H. Ng, A. Iwase, A. Kudo and R. Amal, J. Phys. Chem. Lett., 2010, 1, 2607-2612.

30 C. Nethravathi, T. Nisha, N. Ravishankar, C. Shivakumara and M. Rajamathi, Carbon, 2009, 47, 2054-2059.

31 H. K. Jeong, Y. P. Lee, R. J. W. E. Lahaye, M. H. Park, K. H. An, I. J. Kim, C. W. Yang, C. Y. Park, R. S. Ruoff and Y. H. Lee, J. Am. Chem. Soc., 2008, 130, 1362-1366.

32 C. E. Frey, M. Wiechen and P. Kurz, Dalton Trans., 2014, 43, 4370-4379.

33 A. Iyer, J. Del-Pilar, C. K. King'ondu, E. Kissel, H. F. Garces, H. Huang, A. M. El-Sawy, P. K. Dutta and S. L. Suib, J. Phys. Chem. C, 2012, 116, 6474-6483.

34 M. Kim, Y. Hwang and J. Kim, J. Power Sources, 2013, 239, 225-233.

35 L. G. Cancado, M. A. Pimenta, B. R. A. Neves, M. S. S. Dantas and A. Jorio, Phys. Rev. Lett., 2004, 93.

36 H. Chen, S. X. Zhou, M. Chen and L. M. Wu, J. Mater. Chem., 2012, 22, 25207-25216. 
37 S. Chen, J. W. Zhu, X. D. Wu, Q. F. Han and X. Wang, ACS Nano, 2010, 4, 2822-2830.

38 X. B. Fan, W. C. Peng, Y. Li, X. Y. Li, S. L. Wang, G. L. Zhang and F. B. Zhang, Adv. Mater., 2008, 20, 4490-4493.

39 T. Sukonket, A. Khan, B. Saha, H. Ibrahim, S. Tantayanon, P. Kumar and R. Idem, Energy Fuels, 2011, 25, 864-877.

40 L. Jalowiecki-Duhamel, H. Zarrou and A. D'Huysser, Catal. Today, 2008, 138, 124-129.

41 Y. Q. Zou and Y. Wang, Nanoscale, 2011, 3, 2615-2620.

42 E. Eren, M. Guney, B. Eren and H. Gumus, Appl. Catal., B, 2013, 132, 370-378.

43 C. L. Bao, L. Song, W. Y. Xing, B. H. Yuan, C. A. Wilkie, J. L. Huang, Y. Q. Guo and Y. Hu, J. Mater. Chem., 2012, 22, 6088-6096.

44 N. N. Hong, S. B. Nie, L. Song, Q. L. Tai, P. Zhang, B. B. Wang, X. D. Qian and Y. Hu, Mater. Lett., 2011, 65, 2707-2710.

45 C. L. Bao, Y. Q. Guo, B. H. Yuan, Y. Hu and L. Song, J. Mater. Chem., 2012, 22, 23057-23063.

46 K. C. Cheng, C. B. Yu, W. J. Guo, S. F. Wang, T. H. Chuang and Y. H. Lin, Carbohydr. Polym., 2012, 87, 1119-1123.

47 C. L. Bao, Y. Q. Guo, L. Song, Y. C. Kan, X. D. Qian and Y. Hu, J. Mater. Chem., 2011, 21, 13290-13298.

48 X. Wang, L. Song, H. Y. Yang, W. Y. Xing, B. Kandola and Y. Hua, J. Mater. Chem., 2012, 22, 22037-22043.

49 H. Y. Ma, L. F. Tong, Z. B. Xu and Z. P. Fang, Adv. Funct. Mater., 2008, 18, 414-421.

50 X. F. Wu, L. C. Wang, C. Wu, J. H. Yu, L. Y. Xie, G. L. Wang and P. K. Jiang, Polym. Degrad. Stab., 2012, 97, 54-63.

51 H. M. Zhu, J. H. Yan, X. G. Jiang, Y. E. Lai and K. F. Cen, J. Hazard. Mater., 2008, 153, 670-676.

52 O. Sanz, J. J. Delgado, P. Navarro, G. Arzamendi, L. M. Gandia and M. Montes, Appl. Catal., B, 2011, 110, 231-237.
53 D. Q. Yu, Y. Liu and Z. B. A. Wu, Catal. Commun., 2010, 11, 788-791.

54 C. Zhang, L. Han, W. Liu, H. X. Yang, X. Y. Zhang, X. F. Liu and Y. Z. Yang, CrystEngComm, 2013, 15, 5150-5155.

55 D. Y. Li, X. F. Wu and Y. F. Chen, J. Phys. Chem. C, 2013, 117, 11040-11046.

56 Y. Sun, Q. Liu, S. Gao, H. Cheng, F. Lei, Z. Sun, Y. Jiang, H. Su, S. Wei and Y. Xie, Nat. Commun., 2013, 4, 2899.

57 F. Larachi, J. Pierre, A. Adnot and A. Bernis, Appl. Surf. Sci., 2002, 195, 236-250.

58 X. H. Zheng, Y. G. Du, J. Y. Xiao, Y. F. Lu and C. Y. Liang, Mater. Sci. Eng., A, 2009, 505, 187-190.

59 M. Alexandre, G. Beyer, C. Henrist, R. Cloots, A. Rulmont, R. Jerome and P. Dubois, Macromol. Rapid Commun., 2001, 22, 643-646.

60 S. Z. Guo, C. Zhang, H. D. Peng, W. Z. Wang and T. X. Liu, Compos. Sci. Technol., 2011, 71, 791-796.

61 W. Chen and B. J. Qu, Chem. Mater., 2003, 15, 3208-3213.

62 M. Fang, K. G. Wang, H. B. Lu, Y. L. Yang and S. Nutt, J. Mater. Chem., 2010, 20, 1982-1992.

63 P. Lespade, R. Aljishi and M. S. Dresselhaus, Carbon, 1982, 20, 427-431.

64 R. J. Song, Z. W. Jiang, W. G. Bi, W. X. Cheng, J. Lu, B. T. Huang and T. Tang, Chem.-Eur. J., 2007, 13, 3234-3240.

65 R. J. Song, Z. W. Jiang, H. O. Yu, J. Liu, Z. J. Zhang, Q. W. Wang and T. Tang, Macromol. Rapid Commun., 2008, 29, 789-793.

66 C. Karami, H. Ahmadian, M. Nouri, F. Jamshidi, H. Mohammadi, K. Ghodrati, A. Farrokhi and Z. Hamidi, Catal. Commun., 2012, 27, 92-96. 